\title{
Knockdown of CLN5 inhibits the tumorigenic properties of glioblastoma cells via the Akt/mTOR signaling pathway
}

\author{
JIEXIA XING ${ }^{1},{\text { YING } \text { LI }^{2} \text { and HUILAN ZHAO }}^{3}$ \\ ${ }^{1}$ Department of Neurology, Shandong University of Qilu Hospital, Jinan, Shandong 250012; \\ ${ }^{2}$ Department of Critical Medicine, The Third People's Hospital of Heze, Heze, Shandong 274000; \\ ${ }^{3}$ Department of Geriatrics, Affiliated Hospital of Shandong University of \\ Traditional Chinese Medicine, Jinan, Shandong 250011, P.R. China
}

Received February 21, 2020; Accepted August 18, 2020

DOI: $10.3892 / \mathrm{ol} .2021 .12648$

\begin{abstract}
Gliomas are highly malignant tumors with a rapid progression and poor prognosis. The present study investigated the cellular effects of CLN5-knockdown in the glioblastoma (GBM) U251 and U87MG cell lines. The Cell Counting Kit- 8 and colony formation assays indicated that CLN5-knockdown inhibited the proliferation of GBM cells. Additionally, the results of the Transwell and scratch assays revealed that CLN5-knockdown significantly inhibited migration and invasion, and the flow cytometry analysis confirmed that apoptosis was promoted. Knockdown of CLN5 downregulated the expression levels of MMP-2, Bcl-2, cyclin D1, CDK4 and CDK6, and upregulated the expression levels of Bax and activated caspase-9. Additionally, it blocked GBM cells in the G1-phase and induced early apoptosis. Knockdown of CLN5 inhibited the activation of the Akt and mTOR signaling pathways in GBM by decreasing the levels of phosphorylated (p)-Akt and p-mTOR. The present data suggested that downregulation of CLN5 may be a potential treatment option for GBM. Knockdown of CLN5 inhibited the development of GBM via the inhibition of the Akt and mTOR signaling pathways.
\end{abstract}

\section{Introduction}

Gliomas represent a serious clinical disease, with high malignancy, common recurrence and poor prognosis. According to statistics, in 2015, the prevalence of gliomas accounts for $4-5 \%$ in the world $(1,2)$. At present, the standard treatment is to remove the tumor to the maximum extent using radiotherapy

Correspondence to: Dr Huilan Zhao, Department of Geriatrics, Affiliated Hospital of Shandong University of Traditional Chinese Medicine, 42 Wenhua West Road, Jinan, Shandong 250011, P.R. China

E-mail: zhaohuilan0819@126.com

Key words: CLN5, glioblastoma, U251, U87MG, Akt/mTOR pathway, apoptosis and chemotherapy $(3,4)$, but the 5 -year survival rate is $<5 \%$ worldwide (5). Glioblastoma (GBM) is one of the most malignant, recurrent and invasive tumor types, and is classified as grade 4 according to the World Health Organization nervous system tumor classification system (6). GBM is insidious and invasive, and its clinical symptoms appear relatively late (7). Microsurgical resection, postoperative chemotherapy and radiotherapy are the primary techniques to treat GBM (7). Due to limitations of the anatomical structure, highly invasive growth and high radiation resistance, no marked positive effect on the overall prognosis of patients has been achieved, despite numerous advances in treatment methods in recent years (7). Novel treatment strategies and drug research and development have become increasingly urgent as this problem remains to be solved $(8,9)$.

With the rapid development of high-throughput sequencing and bioinformatics in recent years, some key biomarkers and signaling pathways in the development of GBM have been identified, providing a theoretical basis for the study of GBM-targeting drugs (10). The PI3K-Akt-mTOR signaling pathway is a key regulator of numerous cellular processes, including cell proliferation, apoptosis, migration and invasion (11). It is one of the most commonly altered signal transduction networks in human cancer (11). The PI3K family of lipid kinases is a key component of this signaling pathway, and therefore PI3K has become a research hotspot for targeted drugs (12).

The PI3K/Akt/mTOR signaling pathway is composed of three main acting molecules, namely $\mathrm{PI} 3 \mathrm{~K}, \mathrm{PKB} / \mathrm{Akt}$ and mTOR, and it is a central regulatory mechanism that can promote the growth and proliferation of tumor cells and inhibit autophagy (13). Neuroceroid lipofuscins (NCLs) are a common cause of neurodegeneration in children (14). The sixth known NCL gene is CLN5, which is predicted to encode a novel protein with two putative transmembrane domains (15). The CLN5 protein is a 407-amino acid, highly glycosylated protein with unknown functions. It is localized to lysosomes through the mannose-6-phosphate receptor pathway and other signaling pathways (16). Pathogenic mutations result in its retention in the ER/Golgi matrix (17). Lysosomes can effectively control autophagy (18). Recently, researchers examined the association between mTORC1 activation and 
lysosomal localization through CRISPR/Cas9 knockout of lysosomal localization-associated protein components, revealing that limbic lysosomes could facilitate the activation of the mTORC1, mTORC2 and Akt signaling pathways (19). Therefore, the current study speculated that CLN5 may serve a role in GBM. In the present study, the effect of CLN5 on GBM was investigated at the molecular level.

\section{Materials and methods}

Agents. Antibodies against CDK4 (cat. no. 11026-1-AP; 1:1,000), CDK6 (cat. no. 14052-1-AP; 1:1,000), Akt (cat. no. 10176-2-AP; 1:1,000), mTOR (cat. no. 20657-1-AP; 1:1,000), GAPDH (cat. no. 10494-1-AP; 1:1,000) and HRP-conjugated sheep anti-rabbit/mouse (ES-0005, 1:5,000) were ordered from the ProteinTech Group, Inc. Antibodies against CLN5 (cat. no. ab170899; 1:1,000), Bcl-2 (cat. no. ab32124; 1:1,000), Bax (cat. no. ab32503; 1:1,000), phosphorylated (p)-Akt (cat. no. ab38449; 1:1,000), cyclin D1 (cat. no. ab134175; 1:1,000), pro-caspase-9 (cat. no. ab138412; 1:1,000), activated-caspase-9 (cat. no. ab219590; 1:1,000), and p-mTOR (cat. no. ab109268; 1:1,000) were ordered from Abcam.

Gene expression profiling interactive analysis (GEPIA). The expression of CLN5 and overall survival were analyzed using GEPIA (http://gepia.cancer-pku.cn/), which include data from The Cancer Genome Atlas (http://www.tcga.org/) and the Genotype-Tissue Expression (http://commonfund.nih. gov/GTEx/) databases. For the analysis of gene expression, $\log _{2}$ (Transcripts Per Million + 1) was use for log-scale. The cut-off of ILog2 fold-changel was 1 and $\mathrm{P}<0.01$ was considered to indicate a statistically significant difference. The log-rank test, also known as Mantel-Cox test, was used for the analysis of overall survival.

Cell lines and cell culture. U251 and U87MG (glioblastoma of unknown origin) cell lines were purchased from The Cell Bank of Type Culture Collection of the Chinese Academy of Sciences, Shanghai, China and authenticated via STR profiling. The cells were cultured in DMEM supplemented with $10 \%$ FBS (both from Gibco; Thermo Fisher Scientific, Inc.), streptomycin $(100 \mu \mathrm{g} / \mathrm{ml})$ and penicillin $(100 \mathrm{U} / \mathrm{ml})$ in a $5 \% \mathrm{CO}_{2}$ incubator at $37^{\circ} \mathrm{C}$. The cells were washed with PBS 3 times at the logarithmic growth stage, then digested with $0.25 \%$ trypsin for 3-4 min and seeded in a 6 -well plate for subsequent experiments.

Transfection. Transfection was performed according to the instructions for the Lipofectamine ${ }^{\circledR} 2000$ (Invitrogen; Thermo Fisher Scientific, Inc.). The complete culture medium was replaced $2 \mathrm{~h}$ before transfection. The small interfering (si)-CLN5 (OriGene Technologies, Inc.) sequence was 5'-CCT TATTGTCAAGCTAAGT-3' and the negative control (NC) siRNA (OriGene Technologies, Inc.) sequence was 5'-GGC UGUAUGAGCACCGUUATT-3'. A total of $5 \mu 1$ liposome was dissolved into $125 \mu \mathrm{l}$ serum-free and antibiotic-free medium, then mixed gently and left at room temperature for $5 \mathrm{~min}$. Additionally, $5 \mu \mathrm{l}$ si-CLN5 (50 nM) was dissolved into $125 \mu \mathrm{l}$ serum-free and antibiotic-free medium, mixed gently and left at room temperature for $5 \mathrm{~min}$. The liposome solution was mixed with the si-CLN5 solution for $30 \mathrm{~min}$. The cells were washed twice with PBS. The mixture was added into the cells of each well (1x105 cells/well), gently mixed and cultured in the incubator. The cells were incubated at $37^{\circ} \mathrm{C}$ for $24 \mathrm{~h}$, then the complete culture medium was replaced with fresh complete medium, and subsequent experiments were performed after $24 \mathrm{~h}$ of continuous culture.

$R N A$ extraction and reverse transcription-quantitative (RT-q) $P C R$ detection. The Ultrapure RNA kit (CoWin Biosciences) was used to extract the total RNA from cells. After reverse transcription at $85^{\circ} \mathrm{C}$ for 5 min using the Reverse Transcription Reaction kit (CoWin Biosciences), real-time fluorescence qPCR was used to detect the expression levels of CLN5. The thermocycling conditions were as follows: $95^{\circ} \mathrm{C}$ for $5 \mathrm{~min}$, followed by 40 cycles at $95^{\circ} \mathrm{C}$ for $30 \mathrm{sec}, 60^{\circ} \mathrm{C}$ for $45 \mathrm{sec}$ and $72^{\circ} \mathrm{C}$ for $30 \mathrm{~min}$. The primers are listed as follows: CLN5 forward, 5'-CAAGCGCTTTGACTTCCGTC-3' and reverse, 5'-TCA AACCATGTCTCTGCCCC-3'; $\beta$-actin forward, 5'-CCCGAG CCGTGTTTCCT-3' and reverse, 5'-GTCCCAGTTGGTGAC GATGC-3'. Time PCR system was performed using Super TaqMan Mixture (CoWin Biosciences) according to the manufacturer's instructions. $\beta$-actin was used as an internal control. The results were calculated using the $2^{-\Delta \Delta \mathrm{Cq}}$ method (20).

Western blotting. For the immunoblot analysis, the NC and the experimental groups underwent inference for $24 \mathrm{~h}$, then the 6-well plate was placed on ice. RIPA lysis buffer (supplemented with a protease inhibitor; both from CoWin Biosciences) was used to extract total protein, and the protein concentration was determined using a BCA assay (CoWin Biosciences). A total of $20 \mu \mathrm{g}$ protein/lane was separated via 10\% SDS-PAGE gel, and the proteins were then transferred to a PVDF membrane and blocked with $5 \%$ skimmed milk for $1 \mathrm{~h}$ at $37^{\circ} \mathrm{C}$. The membrane was incubated with the aforementioned primary antibodies overnight at $4^{\circ} \mathrm{C}$, washed 3 times (5 min each) with TBS-Tween-20 $(0.05 \%$; v/v) and then incubated with the respective secondary antibodies for $1 \mathrm{~h}$ at room temperature. ECL (EMD Millipore) was used to visualize the protein bands after the membrane was washed. Quantity One 4.6 software (Bio-Rad Laboratories, Inc.) was used to calculate the gray value.

Cell proliferation and viability assays. Proliferation was assessed using the Cell Counting Kit-8 (CCK-8; Beijing Solarbio Science \& Technology, Co., Ltd.) and colony formation assays. According to the manufacturer's protocol, after $24 \mathrm{~h}$ of transfection, the cells were digested and counted, and 2,000 cells/well were seeded in a 96-well plate. The cells were then cultured in an incubator at $37^{\circ} \mathrm{C}$ for $1 \mathrm{~h}$. A total of $10 \mu \mathrm{l}$ CCK- 8 reagent was added and incubated at $37^{\circ} \mathrm{C}$ for $1 \mathrm{~h}$ before detection. Every $24 \mathrm{~h}$, the absorbance was measured at $450 \mathrm{~nm}$ by a microplate reader.

For colony formation assays, cells were seeded into a 6-cm plate after transfection and incubated for 2 weeks at $37^{\circ} \mathrm{C}$. Subsequently, cells were fixed with methanol for $15 \mathrm{~min}$ at room temperature and stained with Giemsa for $20 \mathrm{~min}$ at room temperature. Colonies with $>10$ cells were counted in 5 random fields. 
Transwell assay for invasion detection. Invasion was evaluated using Transwell chambers (EMD Millipore). Matrigel ${ }^{\circledR}$ (cat. no. 356234, BD Biosciences) was diluted in serum-free medium at the ratio of $1: 6$, and $100 \mu \mathrm{l}$ was added into the upper chamber, then incubated at $37^{\circ} \mathrm{C}$ for $4-6 \mathrm{~h}$. After transfection for $24 \mathrm{~h}, 5 \times 10^{4}$ cells in $500 \mu \mathrm{l}$ serum-free medium were added to the upper chamber, and $500 \mu \mathrm{l}$ complete medium was added to the lower chamber. After overnight incubation at $37^{\circ} \mathrm{C}$, a cotton swab was used to wipe off the remaining cells in the upper chamber. After washing with PBS, cells were fixed with $4 \%$ paraformaldehyde for $30 \mathrm{~min}$ at room temperature and stained with $0.1 \%$ crystal violet for $20 \mathrm{~min}$ at $37^{\circ} \mathrm{C}$, then counted under the fluorescence microscope (magnification, $\mathrm{x} 100)$.

Cell migration assay. The migration of U251 and U87MG cells was detected via scratch assay. After digestion, $5 \times 10^{4}$ cells/well were seeded in a 6 -well plate in $500 \mu \mathrm{l}$ serum-free medium, and cells were cultured until confluency overnight at $37^{\circ} \mathrm{C}$. The cells were scratched and cell migration was recorded every $24 \mathrm{~h}$ under the fluorescence microscope (x40 magnification). The results were processed using ImageJ version 1.8.0 software (National Institutes of Health), and the cell migratory ability was assessed based on the extent of the area of cell migration between the control group and the experimental group.

Gelatinase spectrum. Gelatinase spectrum was used to detect MMP-2 expression. After transfection, the NC and experimental groups were incubated at $37^{\circ} \mathrm{C}$ for $24 \mathrm{~h}$, and were then washed with serum-free DMEM 3 times and cultured for $24 \mathrm{~h}$ at $37^{\circ} \mathrm{C}$. The supernatant was collected via centrifugation in $5,000 \mathrm{x}$ g for $5 \mathrm{~min}$ at $4^{\circ} \mathrm{C}$, diluted with serum-free DMEM without mercaptoethanol and added into each well of the vertical electrophoresis tank. The samples were separated using $10 \%$ SDS-PAGE $(0.5 \mathrm{mg} / \mathrm{ml}$ gelatin). After electrophoresis, the gel was dyed with $0.25 \%$ Coomassie Blue R-250 at room temperature for $4 \mathrm{~h}$ and decolorized with decolorizing liquid (10\% acetic acid) at room temperature for $1 \mathrm{~h}$. Following this process, the gel was imaged using a camera (Olympus Corporation). The gray value was analyzed using Quantity One 4.6 software (Bio-Rad Laboratories, Inc.).

Cell apoptosis and cell cycle analysis via flow cytometry. After $24 \mathrm{~h}$ of transfection, the cells were serum-starved for $24 \mathrm{~h}$ and then digested with trypsin for $3-4$ min at $4^{\circ} \mathrm{C}$ without EDTA. Subsequently, they were collected into a centrifuge tube, centrifuged at $300 \mathrm{x}$ g for $5 \mathrm{~min}$ at $4^{\circ} \mathrm{C}$ and resuspended in pre-cooled $\mathrm{PBS}$ at $4^{\circ} \mathrm{C}$. After centrifugation, the cell density was adjusted by adding $1 \mathrm{X}$ binding buffer to obtain $1-5 \times 10^{6}$ cells $/ \mathrm{ml}$. A total of $100 \mu \mathrm{l}$ cell suspension and $5 \mu \mathrm{l}$ Annexin-V/FITC (Beijing 4A Biotech Co., Ltd.) were added into a 5-ml flow tube, incubated at room temperature in the dark for $5 \mathrm{~min}$ according to the manufacturer's protocol, and then $10 \mu \mathrm{II}$ at $37^{\circ} \mathrm{C}$ for $5 \mathrm{~min}$ and $400 \mu \mathrm{l} \mathrm{PBS}$ were added to the mixture before flow cytometry detection. FlowJo version 10.6.2 software (FlowJo LLC) was used to analyze and process the flow cytometry (FACSCanto II; BD Biosciences) results.
For cell cycle detection, ice-cold ethanol was used to fix the cells for $>24 \mathrm{~h}$ at $4^{\circ} \mathrm{C}$. Subsequently, the procedure for cell cycle detection was similar to the aforementioned apoptosis detection. PI was used for single-staining at $37^{\circ} \mathrm{C}$ for $5 \mathrm{~min}$ and $400 \mu \mathrm{l}$ PBS was added. FlowJo software was used to analyze and process the flow cytometry results.

Statistical analysis. Results were analyzed using SPSS 18.0 software (SPSS, Inc.). The comparison between two groups was performed using unpaired Student's t-test. Results were expressed as the mean $\pm \mathrm{SD}$. $\mathrm{P}<0.05$ was considered to indicate a statistically significant difference.

\section{Results}

CLN5 expression is upregulated in GBM. In order to study the association between CLN5 expression and GBM, GEPIA was used to extract RNA sequences from The Cancer Genome Atlas and the Genotype-Tissue Expression databases, in order to further understand the function of this gene (21). The expression levels of CLN5 in GBM tissues were significantly higher compared with those in normal tissues, indicating that CLN5 expression was upregulated in GBM (Fig. 1A). Furthermore, the prognostic survival curve revealed that the overall survival rate of patients with GBM with high CLN5 expression was lower than that of patients with low CLN5 expression; however, there was no significant effect of CLN5 expression on survival (Fig. 1B).

Knockdown of CLN5 decreases the proliferation of GBM cells in vitro. RT-qPCR and western blotting were used to evaluate the efficiency of CLN5-knockdown. The results revealed that CLN5 mRNA and protein expression levels in the si-CLN5 group were significantly decreased in both U251 and U87MG cells compared with those in the NC group (Fig. 2A and B).

The CCK- 8 assay was performed to detect the proliferation of U251 and U87MG cells. The data revealed that after 72 and $96 \mathrm{~h}$ of culture, the proliferative ability of the si-CLN5 group was significantly decreased compared with that of the $\mathrm{NC}$ group $(\mathrm{P}<0.05$; Fig. $2 \mathrm{C})$. In addition, the colony assay demonstrated that the colony formation ability of the si-CLN5 group was significantly lower than that of the NC group ( $\mathrm{P}<0.05$; Fig. 2D). Therefore, CLN5-knockdown significantly inhibited the proliferation of GBM cells in vitro.

CLN5-knockdown inhibits the migration and invasion of GBM cells. The migration of U251 and U87MG cells was detected using the scratch test. The results revealed that the healing area of the si-CLN5 group was decreased compared with that of the $\mathrm{NC}$ group in both cell lines $(\mathrm{P}<0.05$; Fig. 3A), indicating that migration of the si-CLN5 group was inhibited. Transwell assays were performed to evaluate the cell invasive ability. The invasive ability of the si-CLN5 group was significantly decreased compared with that of the NC group in both U251 and U87MG cells ( $\mathrm{P}<0.05$; Fig. 3B). Additionally, gelatinase spectrum was performed to investigate MMP-2 expression, which is an important factor affecting cell migration and invasion. MMP-2 expression in the si-CLN5 group was significantly lower than that in the $\mathrm{NC}$ group $(\mathrm{P}<0.05$; 
A

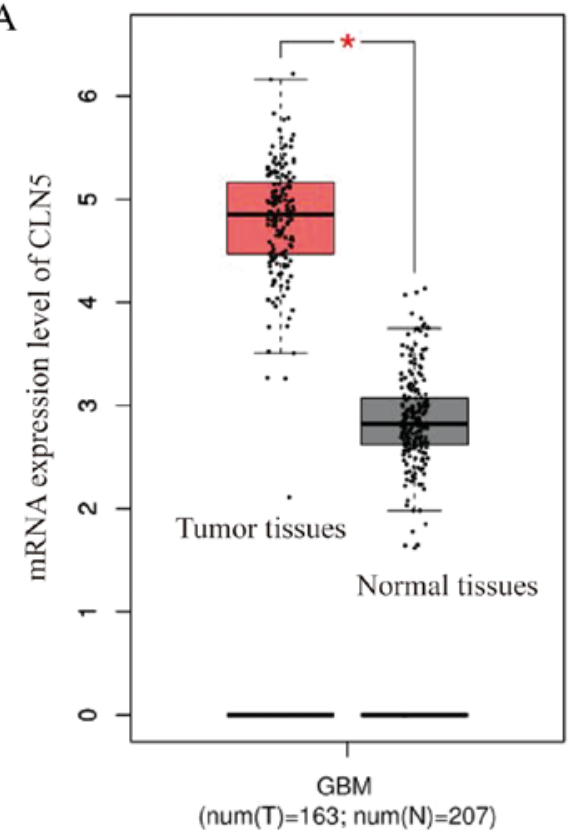

B

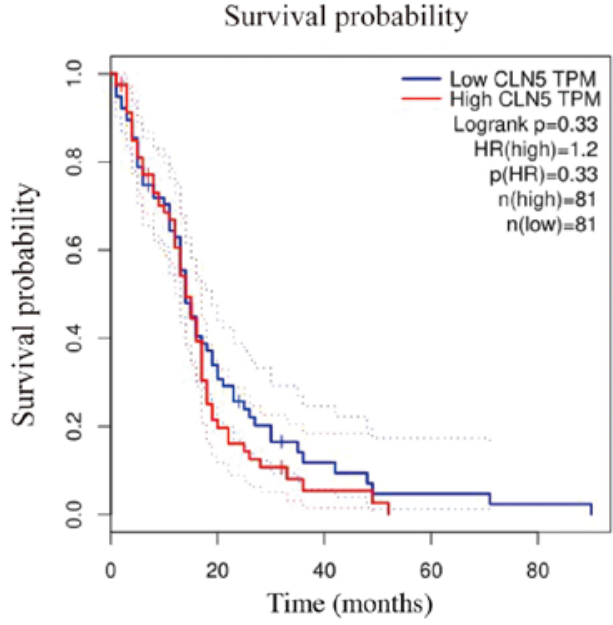

Figure 1. CLN5 expression is upregulated and predicts a poor prognosis in GBM. The expression levels and role in prognosis of CLN5 were assessed using the Gene Expression Profiling Interactive Analysis online database. (A) CLN5 expression was significantly increased in GBM tumor tissues compared with in normal tissues. (B) Overall survival curve based on CLN5 expression. * $\mathrm{P}<0.05$. GBM, glioblastoma; TPM, transcripts per million; T, tumor; N, normal; HR, hazard ratio.

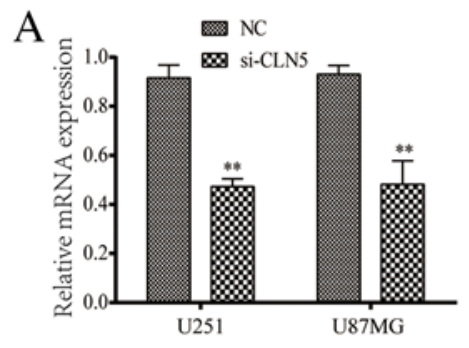

C

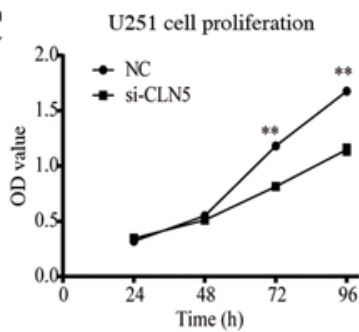

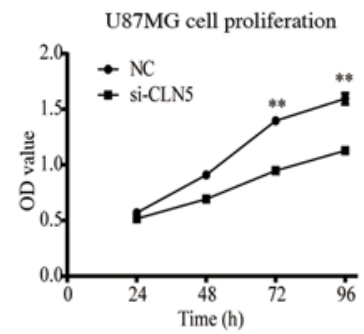
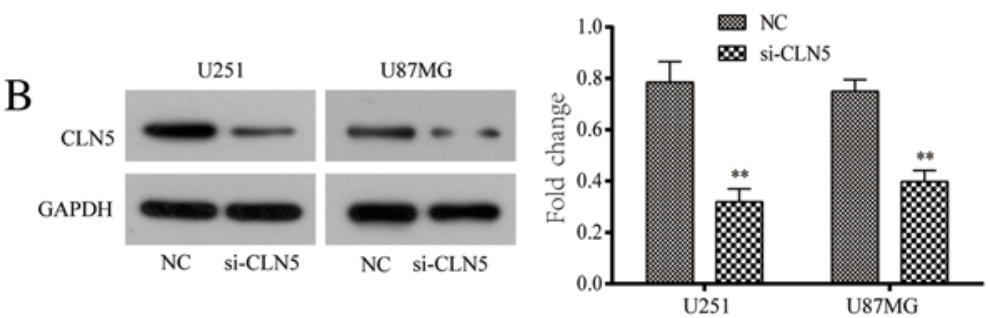

D
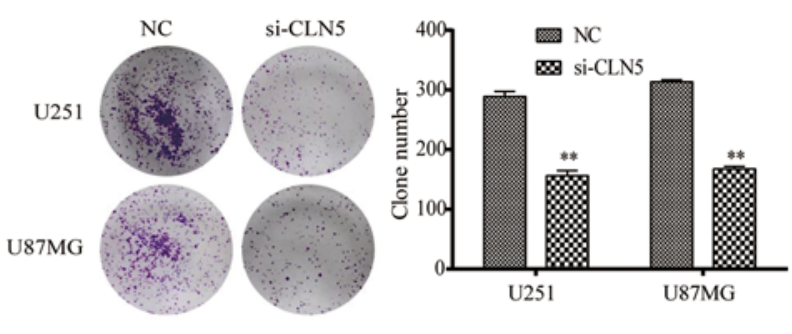

Figure 2. CLN5-knockdown decreases the proliferation of GBM cells. (A) Reverse transcription-quantitative PCR was used to evaluate the mRNA levels of CLN5 using si-CLN5. (B) CLN5 protein expression levels were detected via western blotting. (C) Proliferation curves of U251 and U87MG cells detected using the Cell Counting Kit-8 assay. (D) Colony formation assay was used to evaluate the colony-forming ability of GBM cells (magnification, x100). All experiments were performed in triplicate. ${ }^{* *} \mathrm{P}<0.01$. GBM, glioblastoma; si-CLN5, small interfering RNA against CLN5; OD, optical density.

Fig. 3C). Therefore, the results revealed that CLN5-knockdown inhibited the migration and invasion of GBM cells.

Depletion of CLN5 induces G1-phase arrest in GBM cells. The cell cycle distribution of GBM CLN5-knockdown cells was studied to determine the effect of CLN5 on the cell cycle. Flow cytometry analysis revealed that the number of cells in G1 phase transfected with si-CLN5 was significantly higher than that of $\mathrm{NC}$ cells $(\mathrm{P}<0.05)$, while there was no significant difference between S-phase and G2-phase cells (Fig. 4A). To further explore the regulatory mechanism of G1-phase arrest, the expression levels of cycle-associated molecules such as cyclin D1, CDK4 and CDK6, were analyzed. Compared with NC cells, the expression levels of these proteins in the si-CLN5 group were significantly decreased ( $\mathrm{P}<0.05$; Fig. 4B), suggesting that CLN5-knockdown may inhibit the proliferation of GBM cells by blocking the G1 phase of the cell cycle.

CLN5-knockdown promotes the apoptosis of GBM cells. Due to the abnormal rate of cell proliferation and irregular cell cycle, 
A
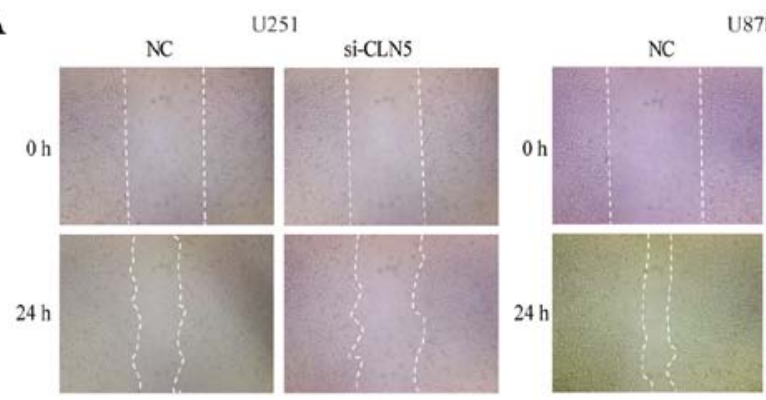

U87MG

si-CLN5

B
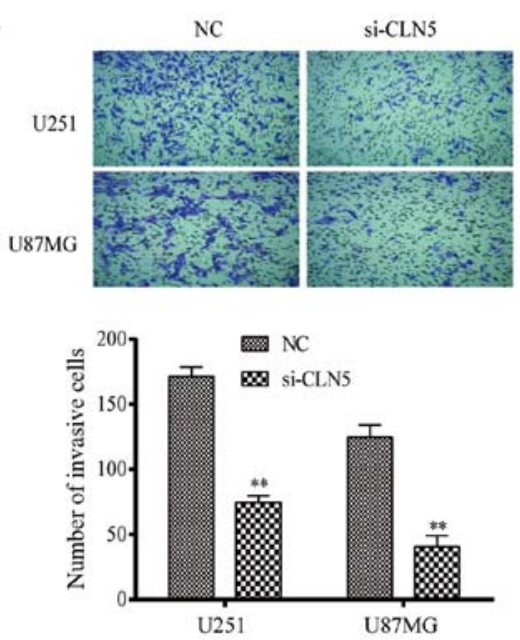

$\mathrm{C}$
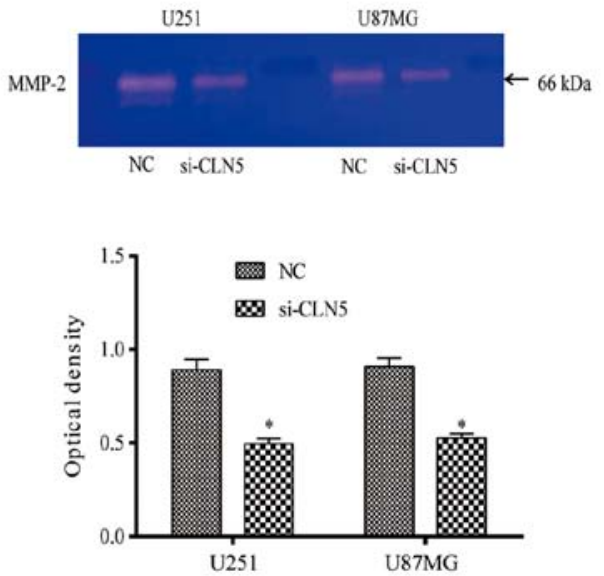

Figure 3. CLN5-knockdown inhibits cell migration and invasion of glioblastoma cells. Knockdown of CLN5 inhibited (A) migration (magnification, x40) and (B) invasion (magnification, x100) of U251 and U87MG cells. (C) MMP-2 expression was evaluated using gelatinase spectrum. All experiments were performed in triplicate. ${ }^{*} \mathrm{P}<0.05 ;{ }^{* * *} \mathrm{P}<0.01$. si-CLN5, small interfering RNA against CLN5.

A
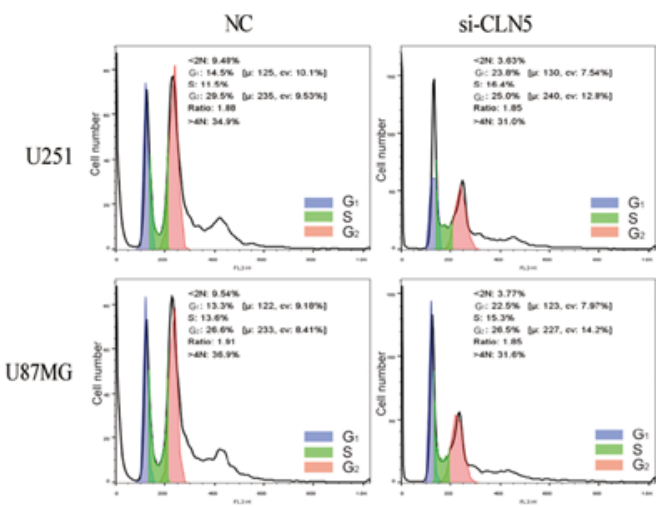
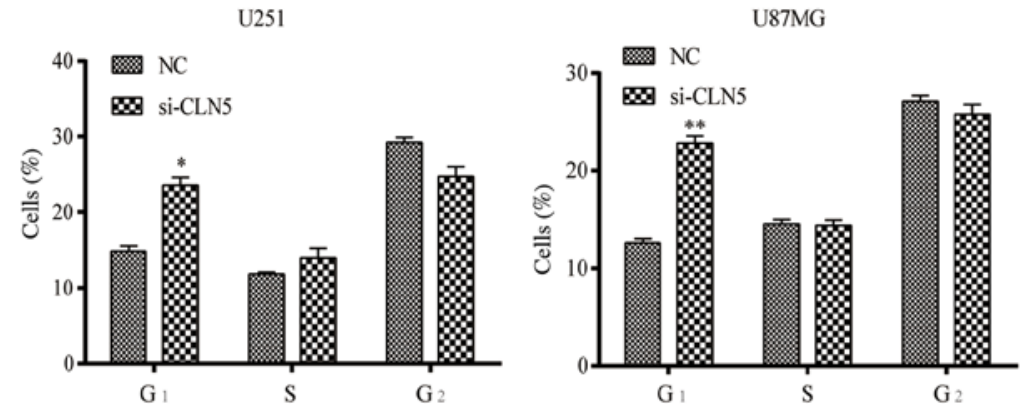

B

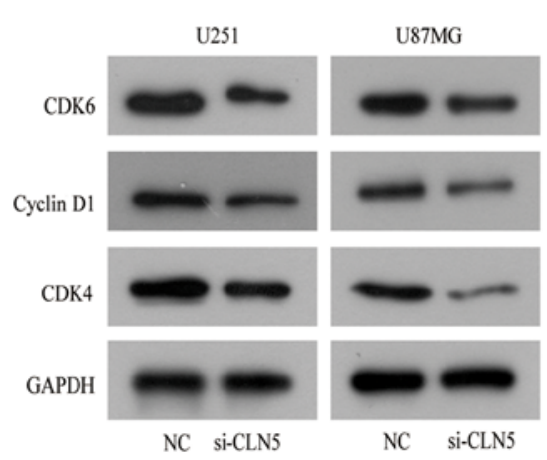

$\mathrm{U} 251$

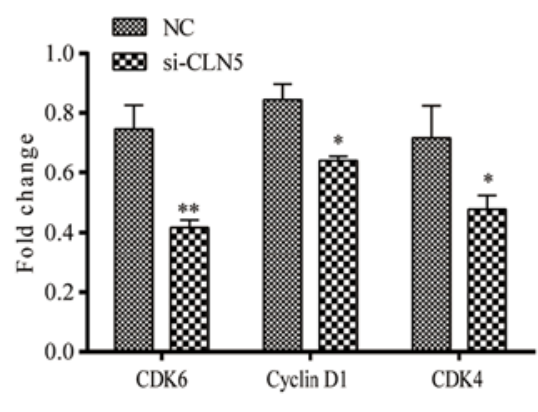

U87MG

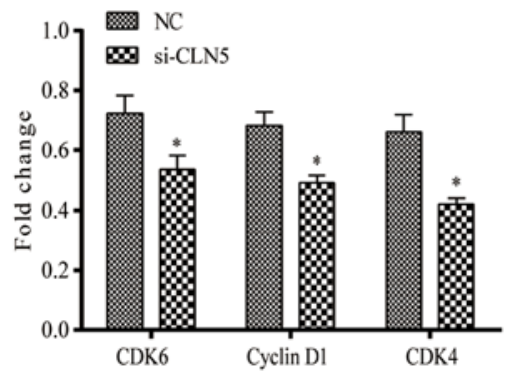

Figure 4. CLN5-knockdown induces G1-phase arrest in glioblastoma cells. (A) Flow cytometry analysis was performed to analyze the cell cycle of U251 and U87MG cells. Green represents FITC and red PI (B) Expression levels of CDK4, CDK6 and cyclin D1 were analyzed via western blotting. All experiments were performed in triplicate. ${ }^{*} \mathrm{P}<0.05 ;{ }^{* *} \mathrm{P}<0.01$. si-CLN5, small interfering RNA against CLN5. 2N, G1 phase; 4N, G2 phase. 
A

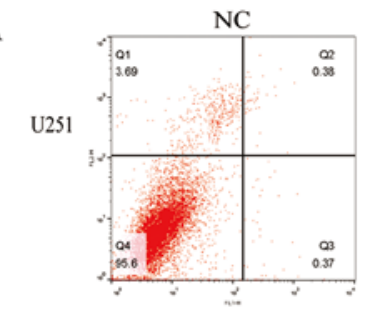

U87MG

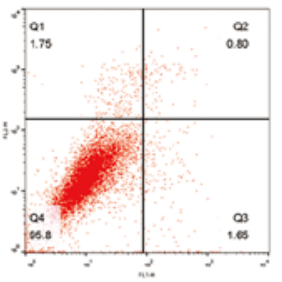

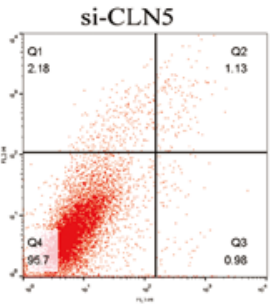

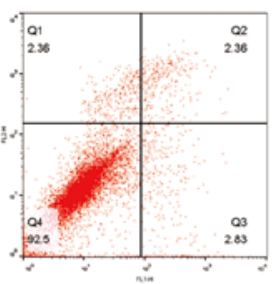

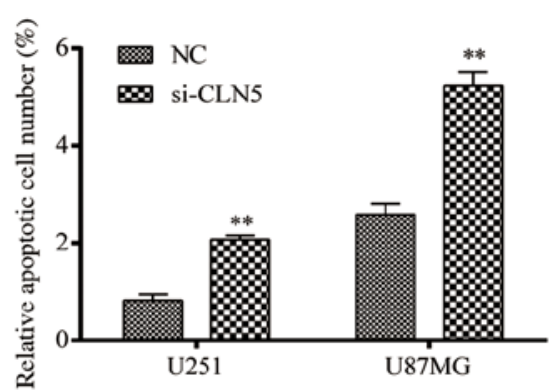

B
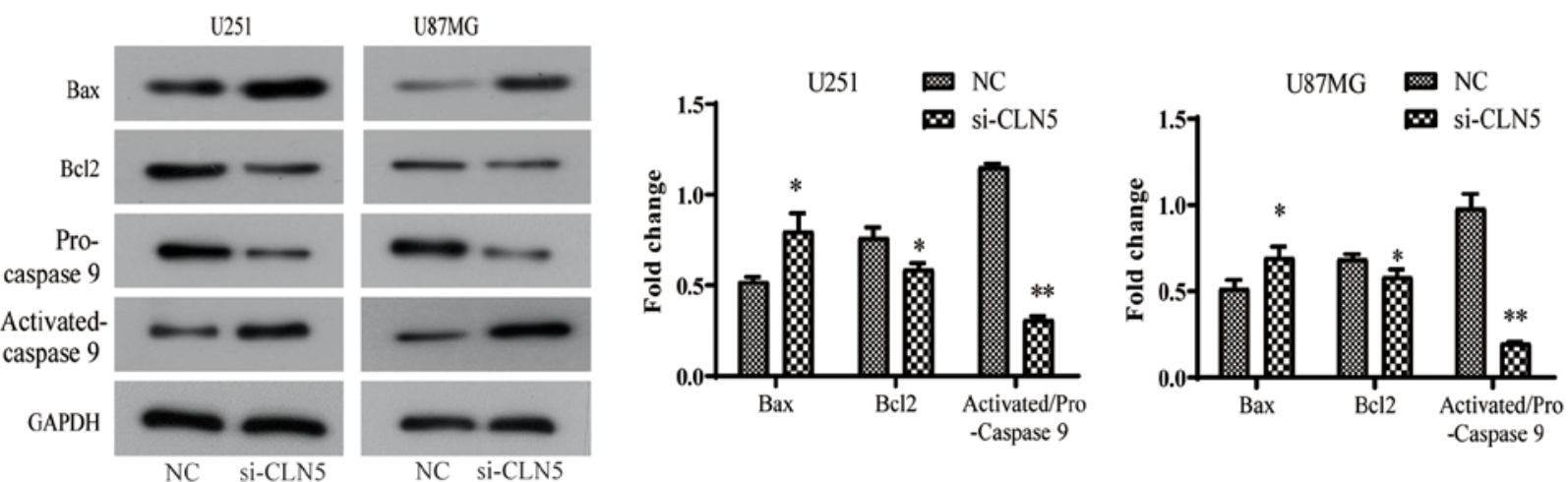

Figure 5. CLN5-knockdown promotes the apoptosis of glioblastoma cells. (A) Apoptosis of U251 and U87MG cells was detected via flow cytometry analysis. (B) Western blot was performed to analyze the expression levels of apoptosis-associated proteins. All experiments were performed in triplicate. ${ }^{\text {* }} \mathrm{P}<0.05$; ${ }^{* *} \mathrm{P}<0.01$. si-CLN5, small interfering RNA against CLN5.

A

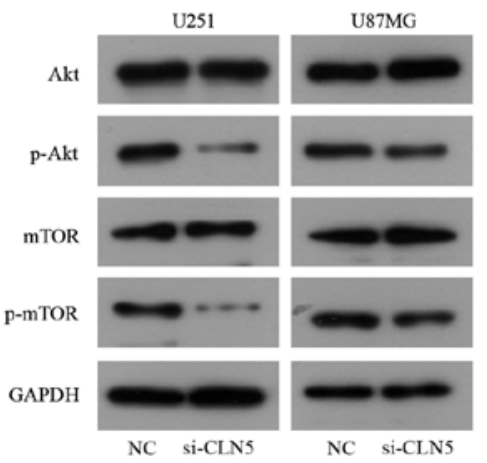

B
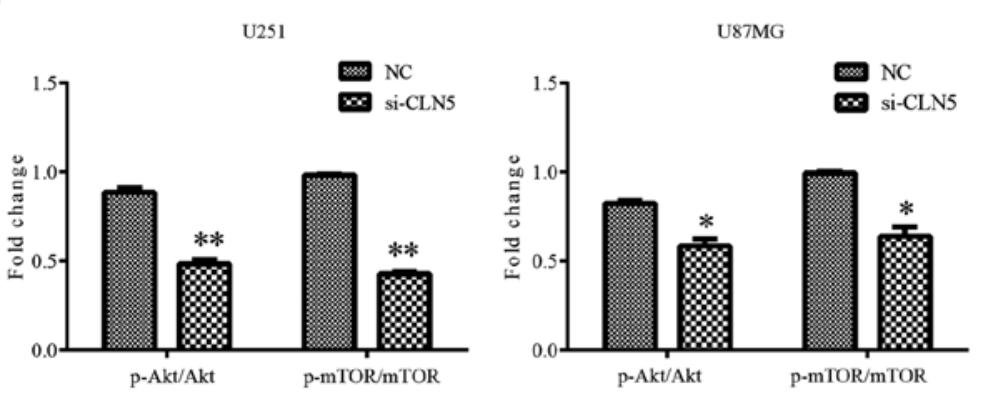

Figure 6. CLN5 serves a role in glioblastoma cells through the stimulation of the AKT/mTOR signaling pathway. (A) Expression levels of Akt and mTOR signaling pathway-associated genes were analyzed via western blotting. (B) Statistical analysis of western blotting results was performed using ImageJ software. ${ }^{*} \mathrm{P}<0.05 ;{ }^{* *} \mathrm{P}<0.01$. si-CLN5, small interfering RNA against CLN5; p, phosphorylated.

the present study further investigated the potential mechanism of the effect of CLN5 on the life cycle of GBM cells. Apoptosis is an important regulator of cell proliferation. Flow cytometry was used to detect apoptosis after Annexin V-FITC and PI double-staining. The results revealed that the apoptosis rate increased significantly after si-CLN5 transfection $(\mathrm{P}<0.05$; Fig. 5A). In addition, changes in the protein expression levels of Bcl-2, activated-caspase- 9 and Bax were investigated, which are closely involved in the process of apoptosis. In the si-CLN5 group, the expression levels of Bax and activated-caspase-9 were increased, while Bcl-2 expression was decreased, indicating that CLN5-knockdown increased the Bax/Bcl-2 ratio (Fig. 5B). In conclusion, the present results revealed that CLN5 may be an important factor in the regulation of apoptosis in GBM cells.

Knockdown of CLN5 inhibits the Akt/mTOR signaling pathway in $G B M$ cells. In order to further explore the mechanism of the effect of CLN5 on GBM, western blotting was used to detect the changes in the Akt/mTOR signaling pathway after 
CLN5-knockdown. The results revealed that there was no significant change in total Akt expression in si-CLN5 cells compared with in the NC group; however, CLN5-knockdown significantly decreased the levels of p-Akt in both U251 $(\mathrm{P}<0.01)$ and U87MG $(\mathrm{P}<0.05)$ cells (Fig. 6). Therefore, it was suggested that CLN5-knockdown inhibited the activation of the Akt signaling pathway in GBM. In addition, changes in the mTOR signaling pathway were analyzed. The inhibitory effect of CLN5-knockdown on the mTOR signaling pathway was similar to that in the Akt signaling pathway, with significantly decreased levels of p-mTOR in the si-CLN5 group compared with in the NC group $(\mathrm{P}<0.01$ in $\mathrm{U} 251$ and $\mathrm{P}<0.05$ in $\mathrm{U} 87 \mathrm{MG}$; Fig. 6). The present results suggested that CLN5 may affect the development of GBM by regulating the Akt/mTOR signaling pathway.

\section{Discussion}

GBM is one of the most lethal types of cancer in humans due to its high malignancy, strong invasion and poor prognosis (22). The CLN5 protein is a 407 amino acid-long glycosylated protein with unknown functions. The present study detected CLN5 upregulation in GBM tissues using GEPIA; therefore, the association between the CLN5 gene and GBM cells was further investigated. The results revealed that CLN5-knockdown effectively inhibited the proliferation and invasion of GBM cells, and promoted apoptosis.

At first, CCK-8 and clone formation assays were used to investigate cell proliferation. It was revealed that CLN5-knockdown effectively inhibited the proliferation of GBM cells in vitro. Subsequently, the cell migratory and invasive abilities were tested, and the results demonstrated that migration and invasion decreased significantly after CLN5-knockdown. In the process of tumor migration and invasion, one of the most important factors is the degradation of the basement membrane and extracellular matrix (23). MMP-2 is a type of multi-matrix metalloproteinase that is involved in the migration and invasion of tumors via the degradation of the extracellular matrix; it is widely involved in numerous pathological processes of tumor development (24) and serves an important role in cancer cells (25). The present results revealed that MMP-2 expression decreased significantly after si-RNA transfection, indicating that CLN5-knockdown may regulate MMP-2 expression and inhibit cell invasion and migration.

In order to further study the role of CLN5 in cell proliferation and apoptosis, the association between CLN5 and the Akt/mTOR signaling pathway was investigated. Cyclins are a family of proteins related to chromosome condensation and mitotic spindle involved in the regulation of the cell cycle $(26,27)$. The results of flow cytometry and western blotting revealed that si-CLN5 downregulated the expression levels of cyclin D1, CDK4 and CDK6, blocked the cell cycle at the G1-phase and induced early apoptosis. In addition, si-CLN5 upregulated the expression levels of Bax and downregulated Bcl-2 expression, which may trigger mitochondrial apoptosis (28). Furthermore, western blotting was used to detect molecules in the Akt/mTOR signaling pathways, and CLN5-knockdown inhibited the activation of the Akt and mTOR signaling pathways in GBM by decreasing the levels of
p-Akt and p-mTOR. However, the antitumor effect of CLN5 has not been verified in mouse models. The mechanism of CLN5 upregulation in glioma and the specific downstream target of CLN5 remain unclear. In the future, further research is required to clarify the regulatory mechanism of CLN5 in human GBM cells.

In conclusion, the present analysis revealed that CLN5-knockdown inhibited proliferation and promoted apoptosis in human GBM cells by potentially inhibiting the Akt and mTOR signaling pathways.

\section{Acknowledgements}

Not applicable.

\section{Funding}

No funding was received.

\section{Availability of data and materials}

All data generated or analyzed during this study are included in this published article.

\section{Authors' contributions}

JX and YL mainly performed the experiments. JX analyzed the data and wrote the manuscript. HZ contributed to analyzing the data and modifying the manuscript. All authors read and approved the final manuscript.

\section{Ethics approval and consent to participate}

Not applicable.

\section{Patient consent for publication}

Not applicable.

\section{Competing interests}

The authors declare that they have no competing interests.

\section{References}

1. Louis DN, Ohgaki H, Wiestler OD, Cavenee WK, Burger PC, Jouvet A, Scheithauer BW and Kleihues P: The 2007 WHO classification of tumours of the central nervous system. Acta Neuropathol 114: 97-109, 2007.

2. Brandsma D, Stalpers L, Taal W, Sminia P and van den Bent MJ: Clinical features, mechanisms, and management of pseudoprogression in malignant gliomas. Lancet Oncol 9: 453-461, 2008.

3. Davis FG, Freels S, Grutsch J, Barlas S and Brem S: Survival rates in patients with primary malignant brain tumors stratified by patient age and tumor histological type: An analysis based on Surveillance, Epidemiology, and End Results (SEER) data, 1973-1991. J Neurosurg 88: 1-10, 2008.

4. Penas-Prado M and Gilbert MR: Molecularly targeted therapies for malignant gliomas: Advances and challenges. Expert Rev Anticancer Ther 7: 641-661, 2007.

5. Tachon G, Masliantsev K, Rivet P, Petropoulos C, Godet J, Milin S, Wager M, Guichet PO and Karayan-Tapon L: Prognostic significance of MEOX2 in gliomas. Mod Pathol 32: 774-786, 2019. 
6. Komori T, Sasaki H and Yoshida K: Revised WHO classification of tumours of the central nervous system: Summary of the revision and perspective. No Shinkei Geka 44: 625-635, 2016 (In Japanese).

7. Wolf A, Agnihotri S and Guha A: Erratum: Targeting metabolic remodeling in glioblastoma multiforme. Oncotarget 9: 34855, 2018.

8. Khosla D: Concurrent therapy to enhance radiotherapeutic outcomes in glioblastoma. Ann Transl Med 4: 54, 2016.

9. Ohgaki $\mathrm{H}$ and Kleihues P: Genetic pathways to primary and secondary glioblastoma. Am J Pathol 170: 1445-1453, 2007.

10. Xu P, Yang J, Liu J, Yang X, Liao J, Yuan F, Xu Y, Liu B and Chen Q: Identification of glioblastoma gene prognosis modules based on weighted gene co-expression network analysis. BMC Med Genomics 11: 96, 2018

11. Gao XF, He HQ, Zhu XB, Xie SL and Cao Y: lncRNA SNHG20 promotes tumorigenesis and cancer stemness in glioblastoma via activating PI3K/Akt/mTOR signaling pathway. Neoplasma 66 : 532-542, 2019.

12. Hudson K, Hancox UJ, Trigwell C, McEwen R, Polanska UM, Nikolaou M, Morentin Gutierrez P, Avivar-Valderas A, Delpuech O, Dudley P, et al: Intermittent high dose scheduling of AZD8835, a novel selective inhibitor of PI3K $\alpha$ and PI3K $\delta$, demonstrates treatment strategies for PIK3CA-dependent breast cancers. Mol Cancer Ther 15: 877-889, 2016

13. Yu JZ, Ying Y, Liu Y, Sun CB, Dai C, Zhao S, Tian SZ, Peng J, Han NP, Yuan JL, et al: Antifibrotic action of Yifei Sanjie formula enhanced autophagy via PI3K-AKT-mTOR signaling pathway in mouse model of pulmonary fibrosis. Biomed Pharmacother 118: $109293,2019$.

14. Mitchison HM and Mole SE: Neurodegenerative disease: The neuronal ceroid lipofuscinoses (Batten disease). Curr Opin Neurol 14: 795-803, 2001

15. Savukoski M, Klockars T, Holmberg V, Santavuori P and Peltonen L: CLN5, a novel gene encoding a putative transmembrane protein mutated in Finnish variant late infantile neuronal ceroid lipofuscinosis. Nat Genet 19: 286-288, 1998.

16. Vesa J, Chin MH, Oelgeschläger K, Isosomppi J,DellAngelica EC, Jalanko A and Peltonen L: Neuronal Ceroid Lipofuscinoses Are Connected at Molecular Level: Interaction of CLN5 Protein with CLN2 and CLN3. Mol Biol Cell 13: 2410-2420, 2002.

17. Lebrun AH, Storch S, Rüschendorf F, Schmiedt ML, Kyttälä A, Mole SE, Kitzmüller C, Saar K, Mewasingh LD, Boda V, et al: Retention of lysosomal protein CLN5 in the endoplasmic reticulum causes neuronal ceroid lipofuscinosis in Asian sibship. Hum Mutat 30: E651-E61, 2009

18. Bouhamdani N, Comeau D, Cormier K and Turcotte S: STF-62247 accumulates in lysosomes and blocks late stages of autophagy to selectively target von Hippel-Lindau-inactivated cells. Am J Physiol Cell Physio 316: C605-C620, 2019.
19. Jia R and Bonifacino JS: Lysosome positioning influences mTORC2 and AKT signaling. Mol Cell 75: 26-38.e3, 2019.

20. Livak KJ and Schmittgen TD: Analysis of relative gene expression data using real-time quantitative PCR and the 2(-Delta Delta $\mathrm{C}(\mathrm{T}))$ method. Methods 25: 402-408, 2001.

21. Tang Z, Li C, Kang B, Ge G, Li C and Zhang Z: GEPIA: A web server for cancer and normal gene expression profiling and interactive analyses. Nucleic Acids Res 45: W98-W102, 2017.

22. Bahadur S, Sahu AK, Baghel P and Saha S: Current promising treatment strategy for glioblastoma multiform: A review. Oncol Rev 13, 417: 2019.

23. Yilmaz M, Christofori G and Lehembre F: Distinct mechanisms of tumor invasion and metastasis. Trends Mol Med 13: 535-541, 2007.

24. Schrump DS, Chen A and Consoli U: Inhibition of lung cancer proliferation by antisense cyclin D. Cancer Gene The 3: 131-135, 1996.

25. Stewart CJ and Crook ML: CD147 (EMMPRIN) and matrix metalloproteinase-2 expression in uterine endometrioid adenocarcinoma. Pathol Res Pract 207: 30-36, 2011.

26. Hoshyar R, Bathaie SZ and Sadeghizadeh M: Crocin Triggers the apoptosis through increasing the $\mathrm{Bax} / \mathrm{Bcl}-2$ ratio and caspase activation in human gastric adenocarcinoma, AGS, cells. DNA Cell Biol 32: 50-57, 2013.

27. Viallard JF, Lacombe F, Belloc F, Pellegrin JL and Reiffers J: Molecular mechanisms controlling the cell cycle: Fundamental aspects and implications for oncology. Cancer Radiother 5: 109-129, 2001 (In French).

28. Yang HL, Kuo YH, Tsai CT, Huang YT, Chen SC, Chang HW, Lin E, Lin WH and Hseu YC: Anti-metastatic activities of Antrodia camphorata against human breast cancer cells mediated through suppression of the MAPK signaling pathway. Food Chem Toxicol 49: 290-298, 2011.

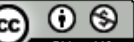

This work is licensed under a Creative Commons Attribution 4.0 International (CC BY-NC 4.0) License 